\title{
Expression and function of ABCG2 in head and neck squamous cell carcinoma and cell lines
}

\author{
BIN SHEN, PIN DONG, DAWEI LI and SHANG GAO \\ Department of Otolaryngology - Head and Neck Surgery, \\ Shanghai Jiaotong University Affiliated First People's Hospital, 200080 Shanghai, P.R. China
}

Received April 4, 2011; Accepted July 28, 2011

DOI: $10.3892 /$ etm.2011.331

\begin{abstract}
Overexpression of breastcancerresistanceprotein, the ATP-binding cassette, subfamily G, member2(BCRP/ABCG2), confers multidrug resistance to tumor cells and often limits the efficacy of chemotherapy. The aim of this study was to investigate the expression and functional activity of ABCG2 in head and neck squamous cell carcinoma (HNSCC) and corresponding cell lines. Immunohistochemistry was performed to investigate the presence of the ABCG2 transporter in HNSCC tissues. Expression of ABCG2 in the Hep-2, Hep-2T, CNE and $\mathrm{FaDu}$ cell lines was analyzed by real-time quantitative reverse transcription-polymerase chain reaction and Western blotting at the levels of messenger RNA (mRNA) and protein, respectively. The drug sensitivity of the above four cell lines to mitoxantrone was detected using MTT, and the drug accumulation of mitoxantrone was analyzed by flow cytometry. Positive expression of ABCG2 was detected in $52.04 \%$ of the laryngeal cancer samples from 98 patients, in $65 \%$ of the 40 hypopharyngeal cancer samples and in $58.82 \%$ of the 34 nasopharyngeal cancer samples. The level of expression was found to be correlated with tumor TNM stage $(\mathrm{P}<0.05)$ and lymph node metastasis $(\mathrm{P}<0.01)$. All four HNSCC cell lines expressed ABCG2 at the mRNA and protein levels. The levels of ABCG2 expression in the four cell lines were significantly correlated with the function and sensitivity to mitoxantrone. The addition of fumitremorgin $\mathrm{C}$ at a concentration of $5 \mu \mathrm{M}$ to mitoxantrone treatment caused a varied increase in mitoxantrone accumulation of 1.09-fold, 1.33-fold $(\mathrm{P}<0.01)$, 1.4-fold $(\mathrm{P}<0.01)$ and 1-fold in the Hep-2, Hep-2T, CNE and FaDu cells, respectively. Expression of ABCG2 varied among the different types of carcinoma tissues and each HNSCC cell line, and it induced multidrug resistance and separation of cancer stem cells attributing to its efflux pump function. Thus, ABCG2 expression may be an unfavorable prognostic factor
\end{abstract}

Correspondence to: Dr Pin Dong, Department of Otolaryngology Head and Neck Surgery, Shanghai Jiaotong University Affiliated First People's Hospital, 200080 Shanghai, P.R. China

E-mail: dongpin64@yahoo.com.cn

Key words: ABCG2, head and neck squamous cell carcinoma, multidrug resistance, prognosis, mitoxantrone for HNSCC. Due to the negligible expression and function of ABCG2, we suggest that the FaDu cell line is suitable to be a negative control in studies involving HNSCC. Taken together, ABCG2 is a promising universal biomarker of cancer stem cells and a target gene for HNSCC chemotherapy.

\section{Introduction}

Approximately 500,000 cases of head and neck squamous cell carcinoma (HNSCC) are diagnosed worldwide each year (1). The main treatment for localized (stages I and II) HNSCC is surgical resection. However, for loco-regionally advanced stage HNSCC (stages III and IV), the benefits of surgery are much less apparent as most patients eventually present with recurrence (2). Moreover, approximately two-thirds of these patients have advanced disease with large primary tumors and/ or regional lymph node involvements (T3-4/N2-3 and M0-1) at the time of diagnosis (3). Thus, the conventional treatment for these patients is chemotherapy or radiotherapy. However, broad resistance, termed multidrug resistance (MDR), to chemotherapy has been found to be a major cause for the failure of HNSCC treatment (4). Among the many reasons for MDR, it has been reported that the family of ATP-binding cassette (ABC) transporters plays a critical role (5).

ATP-binding cassette, subfamily G, member 2 (ABCG2), is a member of the $\mathrm{ABC}$ transporter family, which was first cloned from doxorubicin-resistant human MCF-7 breast cancer cells and was named breast cancer resistance protein (BCRP) (6). ABCG2 overexpression has been observed in many cell lines and tumor types (7-16), where it functions to pump a wide variety of endogenous and exogenous compounds out of cells (17-21). ABCG2 was demonstrated to be associated with cancer stem cells and multidrug resistance $(22,23)$. However, the levels of ABCG2 expression in laryngeal, hypopharyngeal and nasopharyngeal cancers are not known. In addition, the correlation between the level of expression and clinical characteristics also remains to be determined. In the present study, to explore the role of ABCG2 in HNSCC, we examined ABCG2 expression at the protein and mRNA levels, as well as the function of ABCG2 in cell cultures by Western blotting, real-time quantitative reverse transcription-polymerase chain reaction (RT-PCR) and flow cytometry.

Positive ABCG2 expression was observed in HNSCC tissues by immunohistochemistry. The level of ABCG2 
expression was associated with TNM stage and lymph node metastasis. Furthermore, the level of ABCG2 protein and mRNA expression varied among the Hep-2, Hep-2T, CNE and FaDu cell lines. Due to the negligible expression and function of ABCG2 in the FaDu cell line, it is suggested as a negative control cell line in HNSCC study. Additionally, consistent with previous studies, fumitremorgin C (FTC), a specific inhibitor of ABCG2, altered the sensitivity of ABCG2-overexpressing cell lines to mitoxantrone.

\section{Materials and methods}

Cell lines and reagents. The CNE, Hep-2 and FaDu cell lines from human nasopharyngeal, laryngeal and hypopharyngeal cancers, were obtained from the American Type Culture Collection (ATCC). A taxol-resistant cell line (Hep-2T) was developed by continuous exposure of Hep-2 cells to stepwise escalating concentrations of taxol for 12 months (24). All of the cell lines were cultured in Dulbecco's modified Eagle's medium (DMEM), supplemented with $10 \%$ fetal bovine serum, $100 \mathrm{U} / \mathrm{ml}$ penicillin and $100 \mu \mathrm{g} / \mathrm{ml}$ streptomycin at $37^{\circ} \mathrm{C}$ in a humidified atmosphere composed of $5 \% \mathrm{CO}_{2}$.

Mitoxantrone and FTC were purchased from SigmaAldrich (USA). The monoclonal anti-ABCG2 antibody, BXP-21, was purchased from Abcam (USA).

Immunohistochemistry. A panel of untreated HNSCC tissue samples, including 98 cases of laryngeal cancer, 40 cases of hypopharyngeal cancer and 34 cases of nasopharyngeal cancer tissues, was obtained from the Shanghai Jiao Tong University Affiliated First People's Hospital, with approval from the Research Ethics Committee of Shanghai Jiao Tong University Affiliated First People's Hospital. Tissues were fixed in formalin and embedded in paraffin. Serial sections $(4-\mu \mathrm{m})$ were cut and dried for $3 \mathrm{~h}$ at $60^{\circ} \mathrm{C}$. Sections were then deparaffinized with xylene and rehydrated through a graded series of alcohol. Endogenous peroxidase was blocked with $3 \% \mathrm{H}_{2} \mathrm{O}_{2}$, and incubation was carried out with normal goat serum for $30 \mathrm{~min}$ at room temperature. The sections were incubated with BXP-21 (1:40 dilution) overnight at $4^{\circ} \mathrm{C}$. After washing with PBS, sections were incubated for $30 \mathrm{~min}$ with a horseradish peroxidase-labeled polymer anti-mouse secondary antibody. DAB was applied for $40 \mathrm{~min}$ to visualize immunolabeling, resulting in a brown precipitate. After washing, the sections were counterstained with hematoxylin. Negative controls involved substitution of the primary antibody with PBS at the same concentration.

Western blot analysis of ABCG2. Exponentially growing cells were washed two times with ice-cold PBS, and lysed in RIPA buffer with protease inhibitor PMSF for $30 \mathrm{~min}$ with occasional rocking followed by centrifugation at $12,000 \mathrm{x}$ g at $4^{\circ} \mathrm{C}$ for $15 \mathrm{~min}$. Protein concentration of the lysates was quantified by the BCA protein assay. Equal amounts of protein $(40 \mu \mathrm{g})$ were electrophoresed in $8 \%$ SDS-PAGE and transferred to PVDF membranes (Millipore, Bedford, MA, USA). The membranes were blocked for $1 \mathrm{~h}$ with 5\% skim milk in PBS, and incubated with anti-ABCG2 mouse monoclonal antibody BXP-21 diluted 1:20 in skim milk at $4^{\circ} \mathrm{C}$ overnight. After washing, membranes were incubated with the corresponding horseradish peroxi- dase-conjugated secondary antibody (Pierce) diluted 1:20,000 in skim milk. The immunocomplexes were visualized with an enhanced chemiluminescence detection kit according to the manufacturer's instructions (Pierce).

Real-time quantitative RT-PCR. Total cellular RNA was isolated from the Hep-2, Hep-2T, CNE and FaDu cells using TRIzol reagent (Invitrogen). Single-stranded oligo(dT)primed cDNA was generated from $2 \mu \mathrm{g}$ of total RNA in a $20-\mu 1$ reaction mixture. The primers used for the analysis of ABCG2 were sense 5'-CTCAGTTTATCCGTGGTG-3' and antisense 5'-AGATGATTGTTCGTCCCT-3' (180 bp), and $\beta$-actin was used as an internal standard (sense primer 5'-ATCATGTTTGAGACCTTCAA-3' and antisense primer 5'-CATCTCTTGCTCGAAGTCCA-3'; 318 bp). The amplification reaction was carried out with $2 \mu \mathrm{l}$ of cDNA product for 27 cycles and each cycle consisted of $95^{\circ} \mathrm{C}$ for $45 \mathrm{sec}, 56^{\circ} \mathrm{C}$ for $45 \mathrm{sec}$ and $72^{\circ} \mathrm{C}$ for $45 \mathrm{sec}$, followed by a final 5-min elongation at $72^{\circ} \mathrm{C}$. The final PCR products were electrophoresed on a $1.5 \%$ agarose gel. Real-time RT-PCR was performed using a LightCycler rapid thermal cycler system (Roche Diagnostics Ltd., Lewes, UK) according to the manufacturer's instructions. Complementary DNA obtained from $2 \mu \mathrm{g}$ RNA and $0.3 \mu \mathrm{l}$ primers were included in the LightCycler-FastStart DNA Master SYBR Green I mix (Roche Diagnostics). The reaction condition was 40 cycles with denaturation for $10 \mathrm{~min}$ at $95^{\circ} \mathrm{C}$, annealing for $30 \mathrm{sec}$ at $58^{\circ} \mathrm{C}$ and extention for $45 \mathrm{sec}$ at $72^{\circ} \mathrm{C}$. To represent the ABCG2 expression level, the ABCG 2 mRNA expression index was used as calculated from the following formula: Value of the ABCG2 gene copy/value of the $\beta$-actin gene copy.

Cytotoxicity assay of cell survival. 3-4,5-Dimethylthiazol2-yl-2,5-diphenyltetrazolium bromide (MTT) assay was employed to assess cell viability. MTT assay is based on the ability of viable cells to reduce soluble yellow MTT to blue formazan crystals. In this assay, the optical density (OD) values represented the absorption of formazan dissolved by dimethyl sulfoxide (DMSO) at $570 \mathrm{~nm}$. Cells $\left(5 \times 10^{3}\right.$ per well) were seeded in quintuplicate in a 96-well plate containing $150 \mu \mathrm{l}$ culture complete medium. After $24 \mathrm{~h}$ of incubation, different concentrations of mitoxantrone were added to the designated wells after the addition of FTC (5 and $10 \mu \mathrm{M})$. After $48 \mathrm{~h}$ of incubation, $20 \mu \mathrm{l}$ of MTT $(5 \mathrm{mg} / \mathrm{ml})$ was added to each well and the cells were further incubated for $4 \mathrm{~h}$ at $37^{\circ} \mathrm{C}$. The medium was removed and the product was dissolved in DMSO. Absorbance was measured at $570 \mathrm{~nm}$ with a spectrophotometer. DMSO (10\%) was selected as a positive control for the cytotoxicity studies.

$\mathrm{IC}_{50}$ values were calculated using SPSS 16.0 software. Each study was performed in triplicate and repeated three times.

Drug accumulation assays. Cellular mitoxantrone accumulation was determined according to the procedure originally reported by Allen et al (25), with some modifications. Briefly, $4 \times 10^{5}$ cells were seeded in 6 -well plates $24 \mathrm{~h}$ prior to the experiment. Incubation with mitoxantrone $(0,0.5,1,5$ and $10 \mu \mathrm{g} / \mathrm{ml}$ ) was performed for $60 \mathrm{~min}$ at $37^{\circ} \mathrm{C}$ and $70-80 \%$ cellular confluency was achieved. Cells were washed with ice-cold PBS, trypsinized and resuspended in medium at a concentration of $4 \times 10^{5}$ cells $/ \mathrm{ml}$. Intracellular fluorescence 

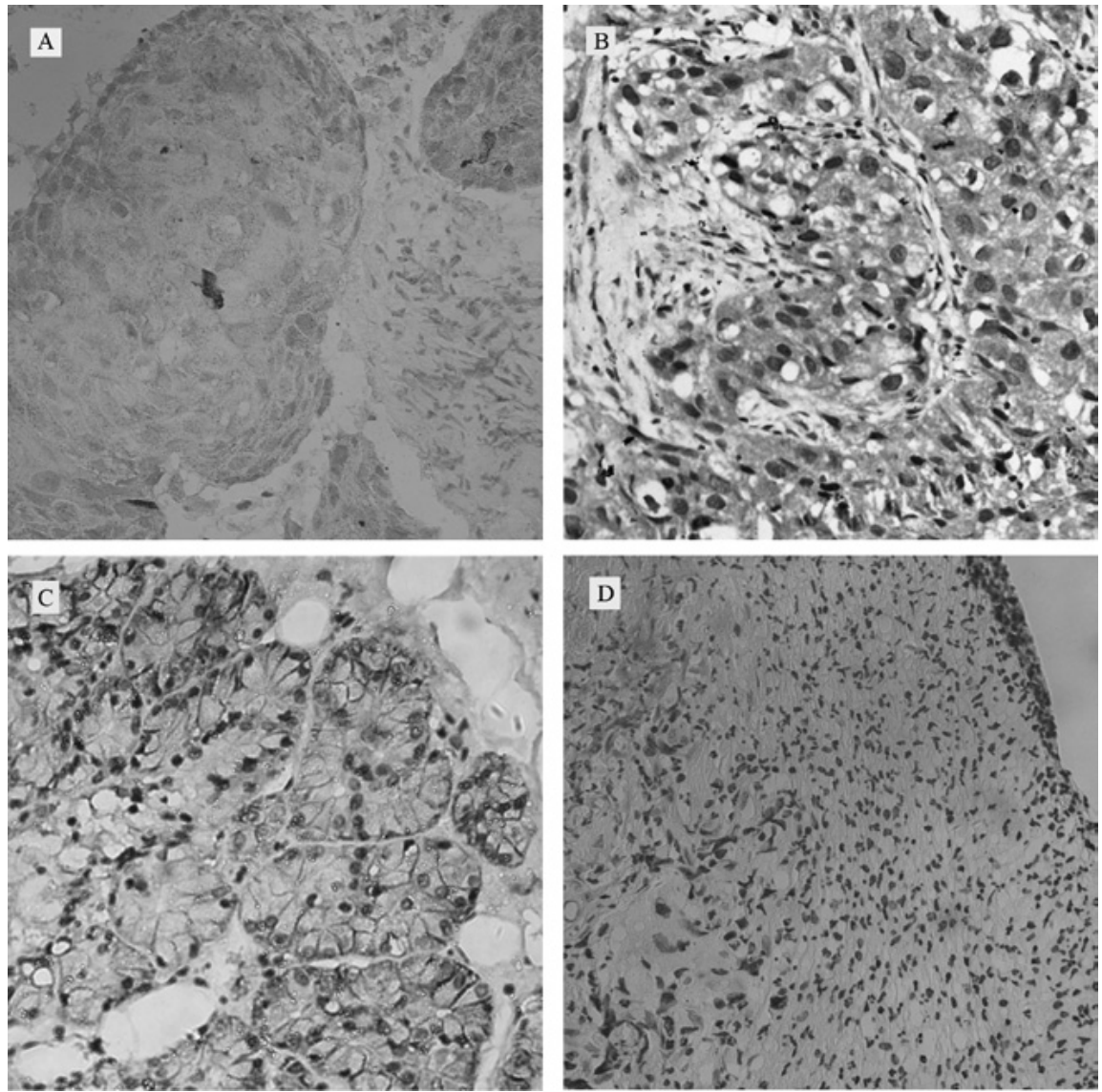

Figure 1. Immunohistochemical analysis of ABCG2 in HNSCC. Expression of ABCG2 in (A) laryngeal, (B) hypopharyngeal and (C) nasopharynx cancer tissues. (D) Negative control of ABCG2 in laryngeal cancer (magnification, x200).

of mitoxantrone was determined by flow cytometry (Becton Dickinson). To measure drug accumulation, cells were then incubated with $0.5 \mu \mathrm{g} / \mathrm{ml}$ mitoxantrone for $1 \mathrm{~h}$ at $37^{\circ} \mathrm{C}$ in the presence or absence of FTC $(5$ and $10 \mu \mathrm{M})$, which was used as an inhibitor of ABCG2 in the four cell lines. The cells were excited at $480 \mathrm{~nm}$ and emission was measured at $630 \mathrm{~nm}$. A minimum of $10^{4}$ cells was analyzed for each sample. All assays were performed in at least three independent experiments, each time with triplicate wells.

Statistical analysis. Categorical variables were evaluated by Pearson Chi-square, continuity correction or Fisher's exact tests. Spearman's rank correlation test was conducted to assess the correlation between ordinal variables. The statistical software SPSS 16.0 was used in data processing and analyzing the significance using the Student's t-test, and a P-value $<0.05$ indicated the presence of a significant difference.

\section{Results}

ABCG2 expression in human HNSCC tissues by immunohistochemistry. Patient epidemiological data, such as median age, gender, tumor grade and stage and lymph node metastasis, were summarized and analyzed (Table I). Positive protein expression of ABCG2 was noted in $52.04 \%$ of the laryngeal, $65 \%$ of the hypopharyngeal and $58.82 \%$ of the nasopharyngeal cancer specimens by immunohistochemistry. ABCG2-positive tumors showed a mixed membranous and cytoplasmic pattern of staining in HNSCC cells (Fig. 1A-C) compared to the negative control of laryngeal cancer (Fig. 1D). Correlations between ABCG2 expression and patient demographic data, as well as various prognostic factors, were also investigated (Table I). High expression of ABCG2 was significantly associated with TNM stage $(\mathrm{P}<0.05)$ and lymph node metastasis $(\mathrm{P}<0.01)$ in the laryngeal and nasopharyngeal cancers, while ABCG2 expression in hypopharyngeal cancer was significantly associated only with lymph node metastasis $(\mathrm{P}<0.01)$. In addition, an increasing trend between ABCG2 expression and clinical TNM stage was noted in the hypopharyngeal cancer.

Western blot analysis and real-time RT-PCR analysis. Fig. 2A illustrates the results of the Western blot analysis of ABCG2 protein expression in the Hep-2, Hep-2T, CNE and FaDu cell lines. Bands detected by chemiluminescence were observed at $\sim 72 \mathrm{kDa}$ corresponding to ABCG2. The levels of ABCG2 markedly varied in the four cell lines (Fig. 2A).

Real-time RT-PCR revealed that the relative expression levels of ABCG2 mRNA in Hep-2, Hep-2T and CNE cells were significantly higher than that in the FaDu cells (Fig. 2B).

The levels of ABCG2 mRNA were consistent with the protein expression in the four cell lines. The taxol-resistant cell line Hep-2T, which was verified by overexpression of P-gp, presented a cross-resistance characteristic corresponding to a much higher expression of ABCG2 than the Hep-2 cells. However, the FaDu cell line exhibited a very low ABCG2 expression at both the protein and mRNA level. 
1154

SHEN et al: ABCG2 EXPRESSION AND FUNCTION IN HNSCC

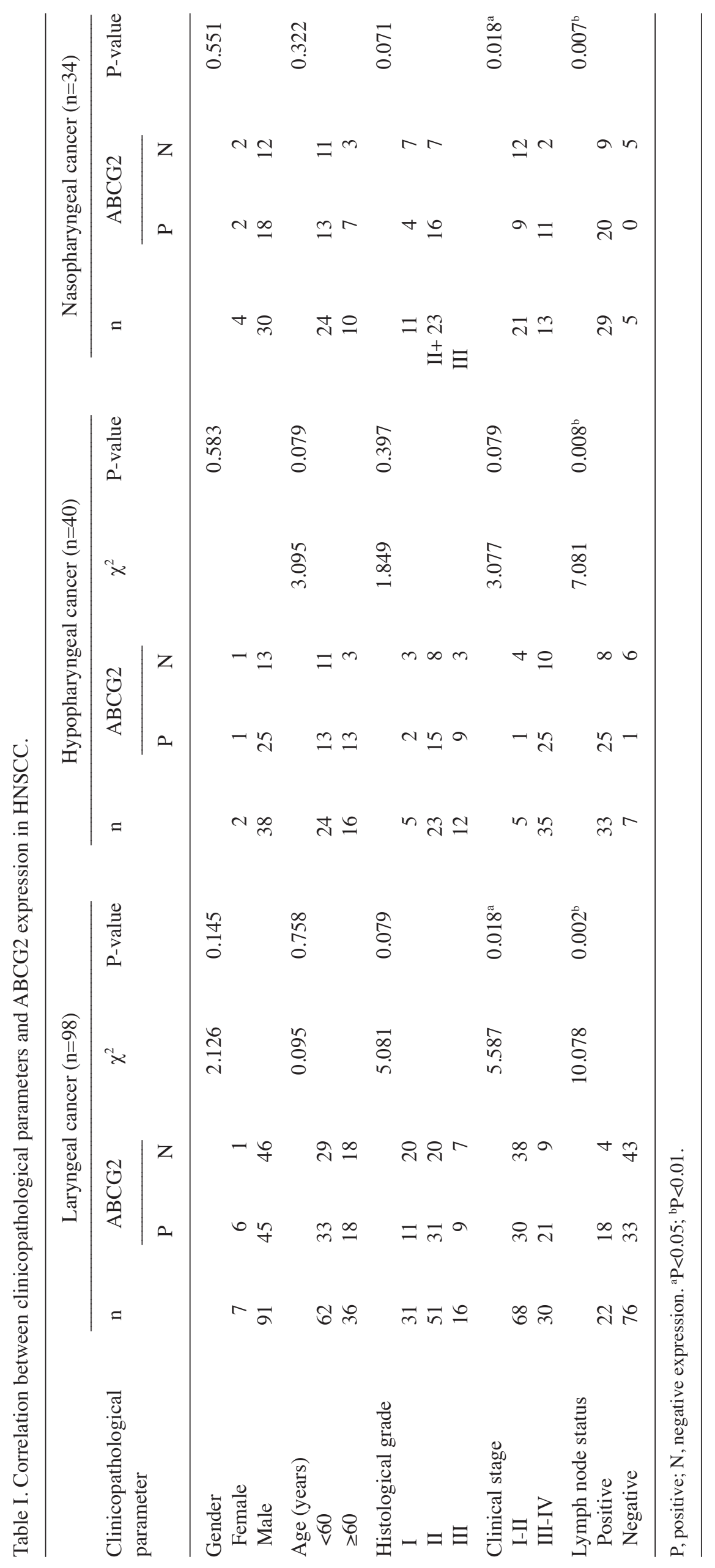


A

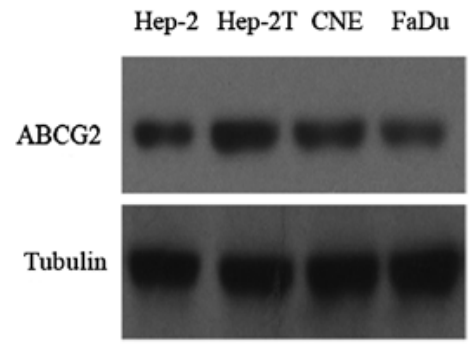

B

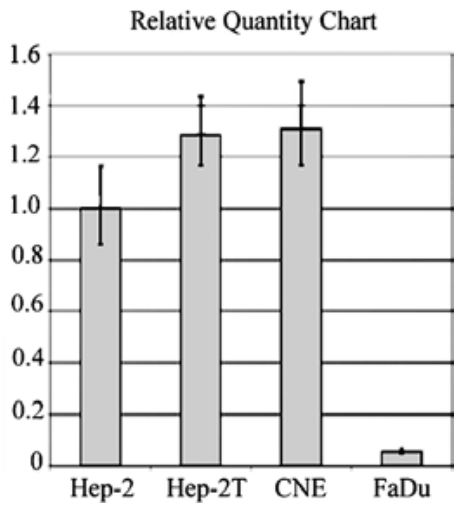

Figure 2. ABCG2 protein and mRNA expression levels in HNSCC cell lines. (A) ABCG2 protein expression was determined by Western blotting using the BXP-21 monoclonal antibody in the four cell lines. (B) The ABCG2 mRNA expression index was calculated by the following formula: Value of the ABCG2 gene copy/value of the $\beta$-actin gene copy.

Table II. Effect of FTC on ABCG2-mediated resistance to mitoxantrone in the HNSCC cell lines.

\begin{tabular}{ccccc}
\hline Compounds & \multicolumn{4}{c}{$\mathrm{IC}_{50} \pm \mathrm{SD} \mu \mathrm{M}$} \\
\cline { 2 - 5 } & Hep-2 & Hep-2T & CNE & FaDu \\
\hline Mitoxantrone & $1.753 \pm 0.244(1.00)$ & $1.817 \pm 0.259(1.00)$ & $1.149 \pm 0.060(1.00)$ & $1.133 \pm 0.540(1.00)$ \\
$+5 \mu$ FTC & $0.638 \pm 0.016(2.75)^{\mathrm{a}}$ & $0.276 \pm 0.047(6.58)^{\mathrm{a}}$ & $0.127 \pm 0.053(9.05)^{\mathrm{a}}$ & $1.126 \pm 0.620(1.00)$ \\
$+10 \mu \mathrm{M}$ FTC & $0.632 \pm 0.032(2.77)^{\mathrm{a}}$ & $0.289 \pm 0.054(6.29)^{\mathrm{a}}$ & $0.093 \pm 0.048(12.35)^{\mathrm{a}}$ & $1.265 \pm 0.427(1.01)$ \\
\hline
\end{tabular}

To examine the effects of FTC on ABCG2-mediated resistance to mitoxantrone in HNSCC cell lines, cells were pre-incubated with or without FTC for $48 \mathrm{~h}$, and then incubated with various concentrations of mitoxantrone. Cell survival was determined by the MTT assay as described in Materials and methods. Data are the means \pm SD of at least three independent experiments performed in triplicate. The fold-reversal of MXR was calculated by dividing the $\mathrm{IC}_{50}$ for cells treated with the anticancer drug in the absence of FTC by that obtained in the presence of FTC. ${ }^{\mathrm{a}} \mathrm{P}<0.01$ for values vs. that obtained in the absence of FTC.

Cytotoxicity assay of cell survival. The sensitivity of the Hep-2, Hep-2T, CNE and FaDu cell lines to mitoxantrone was assessed by MTT assay. The $\mathrm{IC}_{50}$ values of mitoxantrone in the four HNSCC cell lines during treatment alone or in combination with different FTC concentrations are shown in Table II. The fold-reversal value of mitoxantrone by $5 \mu \mathrm{M}$ FTC in Hep-2, Hep-2T and CNE cells was 2.75, 6.58 and 9.05 , respectively. By contrast, FTC did not increase the chemosensitivity of the FaDu cells. As shown in Table II, FTC at the indicated concentrations potently stimulated the activity of mitoxantrone in the Hep-2, Hep-2T and CNE cell lines.

Mitoxantrone accumulation. For the drug accumulation assay, a dose-dependent profile was noted in the Hep2, Hep2T and CNE cells, while the FaDu cell line showed a high level of mitoxantrone uptake. As shown in Fig. 3, the mitoxantrone fluorescence values were inversely correlated with ABCG2 mRNA expression levels. When cells were treated in the presence of 5 and $10 \mu \mathrm{M}$ FTC, the intracellular accumulation of mitoxantrone was 1.09- and 1.12-fold higher in the Hep-2, 1.33- and 1.31-fold higher in the Hep-2T, and 1.4- and 1.5-fold higher in the CNE cells. There was no significant change in the intracellular accumulation of mitoxantrone in the $\mathrm{FaDu}$ cells (Fig. 4).

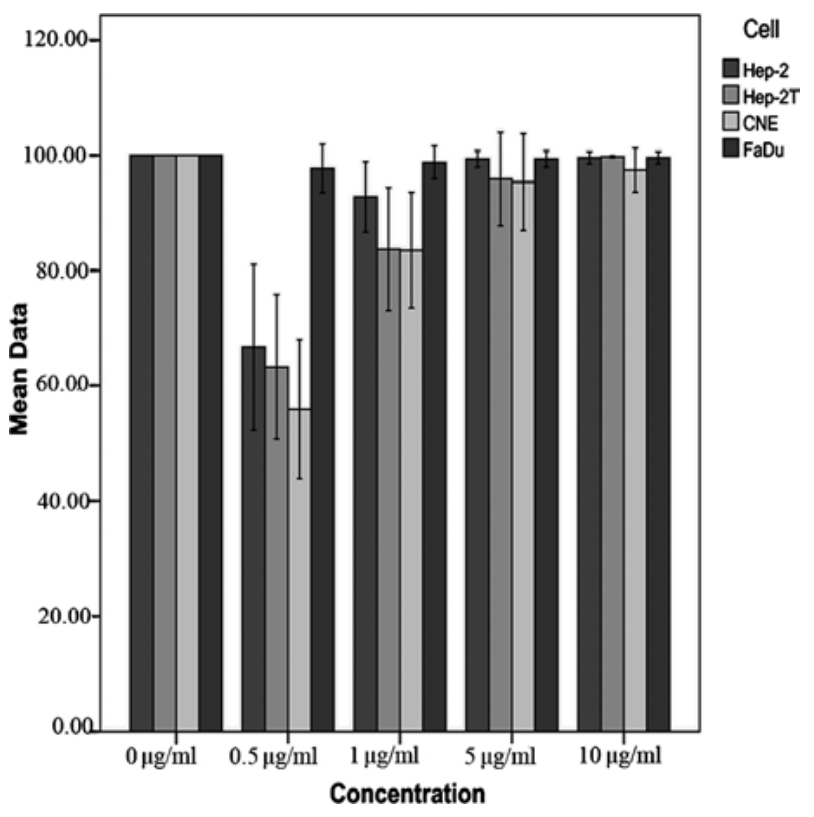

Figure 3. The accumulation of mitoxantrone in the four cell lines was measured by flow cytometry. Cells were seeded in 6 -well plates $24 \mathrm{~h}$ prior to the experiment. Incubation with different concentrations of mitoxantrone was performed for $60 \mathrm{~min}$ at $37^{\circ} \mathrm{C}$ and $70-80 \%$ cell confluency was achieved. The results were presented as fold change in fluorescence intensity relative to the untreated control. Data points represent the means of the different cell lines in three independent experiments. 


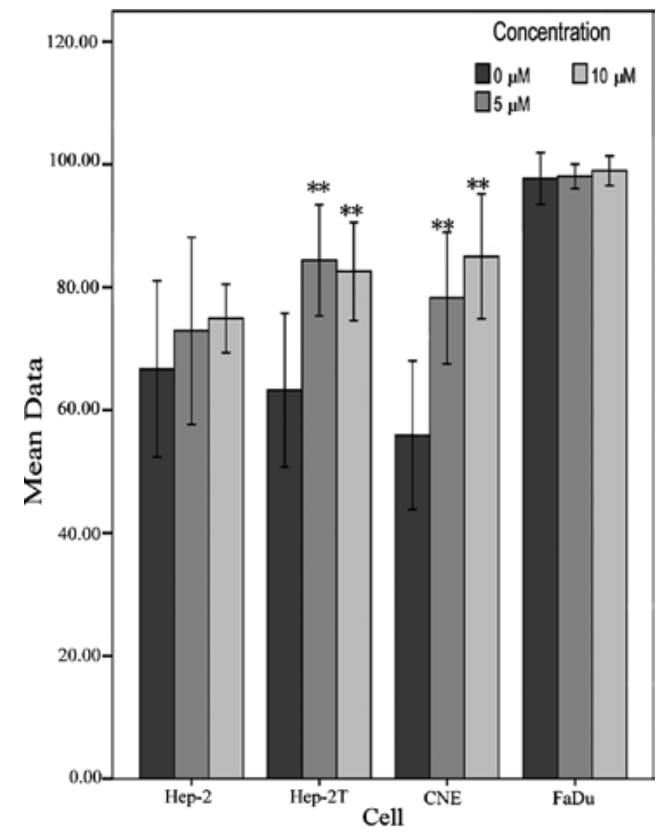

Figure 4. Effect of FTC on the accumulation of mitoxantrone in HNSCC cell lines. The accumulation of mitoxantrone was measured by flow cytometry as described in Materials and methods. Data points represent the means \pm SD of triplicate determinations. ${ }^{*} \mathrm{P}<0.05$ and ${ }^{* *} \mathrm{P}<0.01$ for values vs. those in the control group. Independent experiments were performed at least three times, and a representative experiment is shown.

\section{Discussion}

ABCG2 was discovered a decade ago and has been extensively studied in laboratories worldwide, yielding a wealth of knowledge akin to that gathered for P-gp (26). ABCG2 is a transmembrane transporter that carries out the important biological function of the efflux of multiple endogenous and exogenous substances out of cells. On account of its ability to efflux multiple drugs, overexpression of this protein has been associated with drug-resistant cancers (5), including HNSCC.

In the present study, we first determined the expression of ABCG2 in HNSCC tissues, and similar to the expression in other cancer types, ABCG2-positive tumors showed a mixed membranous and cytoplasmic pattern of staining in HNSCC cells (Fig. 1A-C). In the 98 cases of laryngeal carcinoma, 40 cases of hypopharyngeal carcinoma and 34 cases of nasopharyngeal carcinoma, the ABCG2-positive rate was 52, 65 and $58.8 \%$, respectively. A significant correlation was found between ABCG2 expression and clinical stage and lymph node metastasis. In accordance with research in acute myeloid leukemia $(11,27,28)$, adult acute lymphoblastic leukemia (29), non-small cell lung cancer (15) and esophageal squamous cell carcinoma (14), positive expression of ABCG2 may accelerate progression and metastasis in HNSCC. However, no significant correlation, only an increasing trend between ABCG2 expression and histological grade, was observed in the tumor tissues of the laryngeal and nasopharyngeal cancers. Theoretically, the chemosensitivity of carcinomas usually increases with increasing histological grade. Thus, our results revealed that the drug sensitivity of HNSCC cells is a multifactorial phenomenon, which is determined not only by ABCG2, but by other ABC transporters, such as P-gp. As stated above, it has been demon- strated that ABCG2 may have an effect on disease progression and drug resistance, and it may be an unfavorable prognostic factor of HNSCC. Although the use of targeted molecular agents to cure cancer is promising, one challenge involves the discovery of biomarkers of tumors (30). To our knowledge, this is the first study to investigate the prognostic value of ABCG2 expression in three HNSCC cell lines, simultaneously.

In vitro, $\mathrm{ABCG} 2$ confers drug resistance against a variety of anticancer drugs and isolates stem cell-like side population cells, which may both act as an efflux pump. However, the level of expression of ABCG2 in HNSCC cell lines is not known. In the present study, we evaluated the expression of ABCG2 in four HNSCC cell lines by Western blotting and real-time quantitative RT-PCR (Fig. 2A and B). According to the molecular biological results, the Hep-2T cell line exhibited the highest expression level of ABCG2 protein, followed by CNE, Hep-2 and FaDu cells (Fig. 2A). Consistent with other reports $(31,32)$, the levels of mRNA expression were correlated with the levels of protein expression (Fig. 2B). Based on the above results, we infer that the drug resistance of Hep-2T cells to taxol is not mainly caused by an increased gene and protein level of P-gp expression, but simultaneously by an increased level of ABCG2 expression. Consequently, we found that resistance to a single chemotherapeutic agent may result in cross-resistance to various structurally and functionally dissimilar drugs, as well as elevated expression of different ABC transporters.

In an attempt to evaluate the contribution of resistancerelated molecule $\mathrm{ABCG} 2$, we examined the anticancer drug sensitivity of Hep-2, Hep-2T, CNE and FaDu cell lines to mitoxantrone, as well as the effect of FTC, a specific inhibitor of ABCG2, on the drug sensitivity of the above four HNSCC cell lines (Table II). The results revealed that the ABCG2 protein and mRNA levels reflect the functional activity of ABCG2, and the ability of FTC to reverse these effects may be specific to ABCG2 in HNSCC cell lines. The inhibitor of FTC was not toxic in the four cell lines tested in this study (data not shown). These results clearly demonstrate that inhibition of FTC is more effective in drug-resistance cell lines than in their parental cells. Consistent with cytotoxicity data, the results of the drug accumulation studies showed that FTC strongly enhanced the intracellular accumulation of mitoxantrone in the ABCG2-overexpressing cells. The results confirmed that mitoxantrone is a specific substrate for ABCG2 and FTC is a specific inhibitor of ABCG2 in HNSCC cell lines.

Moreover, the FaDu cell line did not show obvious expression and function of ABCG2. These results indicate that the $\mathrm{FaDu}$ cell line may be suitable as a negative control for the study of ABCG2 in HNSCC cell lines in further investigations.

It is well known that tumors are composed of heterogeneous cell types. Evidence suggests that carcinoma is a disease of stem cells and, similar to normal organs, contains a small population of cells with high proliferative capacity, self-renewing potential, multidifferentiation ability and resistance to chemotherapy and radiotherapy. This has catalyzed a shift towards using targeted therapies for cancer. To date, side-population phenotype cells, which exhibit many characteristics of stem cells, were selected in a wide variety of normal tissues and tumors in an attempt to understand the biological properties of cell types in HNSCC $(33,34)$. Distinct molecular markers of cancer stem cells were absent in these cells, and there is increasing evidence suggesting 
that they may play an important role in tumorigenesis and cancer therapy.

In conclusion, the results of the present study confirmed that ABCG2 is widely present in untreated HNSCC cells, raising the possibility that ABCG2 may be a simple independent unfavorable prognostic factor for HNSCC, and may be a clinically relevant mechanism of anticancer drug resistance. We also confirmed ABCG2 expression and its efflux pump function in HNSCC cell lines; the specific inhibitor of FTC decreased the expression of ABCG2, resulting in an increase in the intracellular concentration of mitoxantrone. Moreover, the FaDu cell line is potentially a suitable negative control for further study of the role of ABCG2 in HNSCC. In future studies, we will focus on the function and characteristics of side-population cells in HNSCC.

\section{Acknowledgements}

The authors are grateful to Dr Jiawei Chen and Dr Honghui Hu of the Department of Pathology, Shanghai Jiaotong University Affiliated First People's Hospital, for the database of clinical indices and the technical assistance. They also thank Ms. Yu-Ying Chen of the Morphology and Cell Chemistry Laboratory of Shanghai Jiao Tong University School of Medicine, for her assistance in the immunohistochemistry. This study was supported by the Shanghai Science and Technology Development Fund (no. 09411951000) and the Resource Sharing Platform for Clinical Research (no. SHDC12007206), China.

\section{References}

1. Greenlee RT, Murray T, Bolden S and Wingo PA: Cancer statistics, 2000. CA Cancer J Clin 50: 7-33, 2000.

2. Vokes EE, Weichselbaum RR, Lippman SM and Hong WK: Head and neck cancer. N Engl J Med 328: 184-194, 1993.

3. Clark JI, Hofmeister C, Choudhury A, et al: Phase II evaluation of paclitaxel in combination with carboplatin in advanced head and neck carcinoma. Cancer 92: 2334-2340, 2001.

4. Dean M, Hamon Y and Chimini G: The human ATP-binding cassette (ABC) transporter superfamily. J Lipid Res 42: 1007-1017, 2001.

5. Ross DD and Nakanishi T: Impact of breast cancer resistance protein on cancer treatment outcomes. Methods Mol Biol 596: 251-290, 2010

6. Doyle LA, Yang W, Abruzzo LV, et al: A multidrug resistance transporter from human MCF-7 breast cancer cells. Proc Nat Acad Sci USA 95: 15665-15670, 1998.

7. Diestra JE,Condom E, del Muro XG, et al: Expression of multidrug resistance proteins P-glycoprotein, multidrug resistance protein 1 , breast cancer resistance protein and lung resistance-related protein in locally advanced bladder cancer treated with neoadjuvant chemotherapy: biological and clinical implications. J Urol 170: 1383-1387, 2003.

8. Sauerbrey A, Sell W, Steinbach D, Voigt A and Zintl F: Expression of the BCRP gene (ABCG2/MXR/ABCP) in childhood acute lymphoblastic leukaemia. Br J Haematol 118: 147-150, 2002.

9. Abbott BL, Colapietro AM, Barnes Y, Marini F, Andreeff M and Sorrentino BP: Low levels of ABCG2 expression in adult AML blast samples. Blood 100: 4594-4601, 2002

10. Plasschaert SL, van der Kolk DM, de Bont ES, et al: The role of breast cancer resistance protein in acute lymphoblastic leukemia Clin Cancer Res 9: 5171-5177, 2003.

11. Benderra Z, Faussat AM, Sayada L, et al: Breast cancer resistance protein and P-glycoprotein in 149 adult acute myeloid leukemias. Clin Cancer Res 10: 7896-7902, 2004.

12. Nakayama K, Kanzaki A, Ogawa K, Miyazaki K, Neamati N and Takebayashi Y: Copper-transporting P-type adenosine triphosphatase (ATP7B) as a cisplatin-based chemoresistance marker in ovarian carcinoma: comparative analysis with expression of MDR1, MRP1, MRP2, LRP and BCRP. Int J Cancer 101: 488-495, 2002
13. Faneyte IF, Kristel PM, Maliepaard M, et al: Expression of the breast cancer resistance protein in breast cancer. Clin Cancer Res 8: 1068-1074, 2002.

14. Tsunoda S, Okumura T, Ito T, et al: ABCG2 expression is an independent unfavorable prognostic factor in esophageal squamous cell carcinoma. Oncology 71: 251-258, 2007.

15. Yoh K, Ishii G, Yokose T, et al: Breast cancer resistance protein impacts clinical outcome in platinum-based chemotherapy for advanced non-small cell lung cancer. Clin Cancer Res 10: 1691-1697, 2004

16. Jin Y, Bin ZQ, Qiang H, et al: ABCG2 is related with the grade of glioma and resistance to mitoxantone, a chemotherapeutic drug for glioma. J Cancer Res Clin Oncol 135: 1369-1376, 2009.

17. Polgar O, Robey RW and Bates SE: ABCG2: structure, function and role in drug response. Expert Opin Drug Metab Toxicol 4: $1-15,2008$.

18. Honjo Y, Hrycyna CA, Yan QW, et al: Acquired mutations in the MXR/BCRP/ABCP gene alter substrate specificity in MXR/ BCRP/ABCP-overexpressing cells. Cancer Res 61: 6635-6639, 2001.

19. Robey RW, Honjo Y, Morisaki K, et al: Mutations at amino-acid 482 in the ABCG2 gene affect substrate and antagonist specificity. Br J Cancer 89: 1971-1978, 2003.

20. Ejendal KFK, Diop NK, Schweiger LC and Hrycyna CA: The nature of amino acid 482 of human ABCG2 affects substrate transport and ATP hydrolysis but not substrate binding. Protein Sci 15: 1597-1607, 2006.

21. Miwa M, Tsukahara S, Ishikawa E, Asada S, Imai Y and Sugimoto Y: Single amino acid substitutions in the transmembrane domains of breast cancer resistance protein (BCRP) alter cross resistance patterns in transfectants. Int J Cancer 107: 757-763, 2003.

22. Song J, Chang I, Chen Z, Kang M and Wang CY: Characterization of side populations in HNSCC: highly invasive, chemoresistant and abnormal Wnt signaling. PloS One 5: e11456, 2010.

23. Schwabedissen HE and Kroemer HK: In vitro and in vivo evidence for the importance of breast cancer resistance protein transporters (BCRP/MXR/ABCP/ABCG2). Handb Exp Pharmacol 201: 325-371, 2011.

24. Li L, Jiang AC, Dong P, Wan Y and Yu ZW: The characteristics of Hep-2 cells with multiple drug resistance induced by Taxol. Otolaryngol Head Neck Surg 137: 659-664, 2007.

25. Allen JD, van Loevezijn A, Lakhai JM, et al: Potent and specific inhibition of the breast cancer resistance protein multidrug transporter in vitro and in mouse intestine by a novel analogue of fumitremorgin C. Mol Cancer Ther 1: 417-425, 2002.

26. Robey RW, To KK, Polgar O, et al: ABCG2: a perspective. Adv Drug Deliv Rev 61: 3-13, 2009.

27. Benderra Z, Faussat AM, Sayada L, et al: MRP3, BCRP, and P-glycoprotein activities are prognostic factors in adult acute myeloid leukemia. Clin Cancer Res 11: 7764-7772, 2005.

28. Uggla B, Stahl E, Wagsater D, et al: BCRP mRNA expression v. clinical outcome in 40 adult AML patients. Leuk Res 29: 141-146, 2005.

29. Suvannasankha A, Minderman H, O'Loughlin KL, et al: Breast cancer resistance protein (BCRP/MXR/ABCG2) in acute myeloid leukemia: discordance between expression and function. Leukemia 18: 1252-1257, 2004.

30. Sawyers CL: The cancer biomarker problem. Nature 452: 548-552, 2008.

31. Maliepaard M, Scheffer GL, Faneyte IF, et al: Subcellular localization and distribution of the breast cancer resistance protein transporter in normal human tissues. Cancer Res 61: 3458-3464, 2001.

32. Young LC, Campling BG, Cole SPC, Deeley RG and Gerlach JH: Multidrug resistance proteins MRP3, MRP1, and MRP2 in lung cancer: correlation of protein levels with drug response and messenger RNA levels. Clin Cancer Res 7: 1798-1804, 2001.

33. Hirschmann-Jax C, Foster AE, Wulf GG, et al: A distinct 'side population' of cells with high drug efflux capacity in human tumor cells. Proc Natl Acad Sci USA 101: 14228-14233, 2004.

34. Haraguchi N, Utsunomiya $\mathrm{T}$, Inoue $\mathrm{H}$, et al: Characterization of a side population of cancer cells from human gastrointestinal system. Stem Cells 24: 506-513, 2006. 
